\title{
fragmentum 22
}

\section{Entre linguas e culturas:}

Uma historia de vida e uma história social

\author{
na Linguistica Aplicada
}

Entrevista com Maria José Coracini

\author{
Beatriz Echert-Hoff \\ Marluza da Rosa \\ (Orgs.)
}




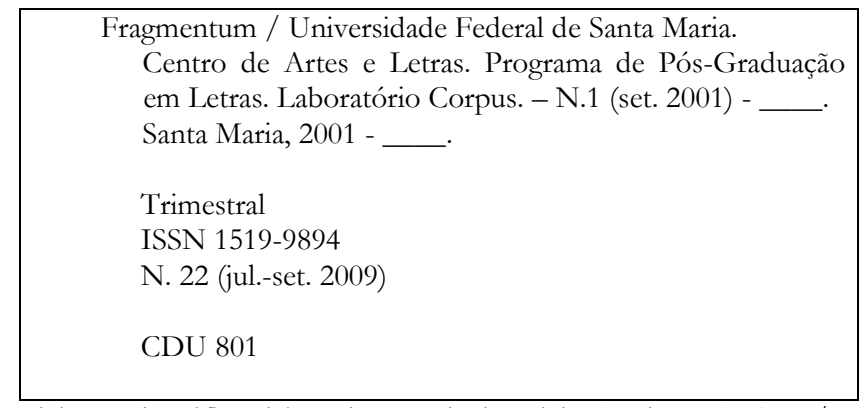

Ficha catalográfica elaborada por Alenir Inácio Goularte CRB-10/990 Biblioteca Central da UFSM

\author{
EDITORA PPGL \\ Impresso na IMPRENSA UNIVERSITÁRIA \\ UFSM - Santa Maria - RS \\ Maio de 2010
}




\title{
Entre linguas e culturas:
}

Uma história de vida e uma história social

\author{
na Linguistica Aplicada
}

Entrevista com Maria José Coracini

\author{
Beatriz Echert-Hoff \\ Marluza da Rosa \\ (Orgs.)
}

FRAGMENTUM No 22, JUL./SET. DE 2009

Laboratório Corpus

Programa de Pós-Graduação em Letras

Centro de Artes e Letras

Universidade Federal de Santa Maria

Santa Maria, RS

ISSN 1519-9894 
fragmentum

Revista do Laboratório Corpus do Programa de Pós-Graduação em Letras UFSM

Reitor

Felipe Martins Müller

Diretor do Centro de Artes e Letras

Edemur Casanova

Coordenadora do Programa de Pós-Graduação em Letras

Amanda Eloina Scherer

Coordenadora Geral do LabCorpus

Amanda Eloina Scherer

Coordenador Executivo do LabCorpus

Pedro Brum Santos

Coordenadora Acadêmico-Cientifica do LabCorpus

VerliPetri

Assistente de Pesquisa do LabCorpus

Rejane Arce Vargas

Pesquisadores do LabCorpus

Amanda Eloína Scherer

Eliana Rosa Sturza

Graziela de Lucci de Angelo

Marcia Cristina Corrêa

Mirian Rose Brum-de-Paula

Pedro Brum Santos

Silvia Paraense 
Tania Regina Taschetto

Vera Lúcía Lenz Víanna

VerliPetri

\section{Corpo Editorial}

Amanda Eloina Scherer (Presidente)

Pedro Brum Santos

VerliPetri

\section{Comitê Editorial}

Ana Zandwais - UFRGS

Beatriz Eckert-Hoff - UNITACVUniAnchieta

Bethania Mariani - UFF

Carme Schons - UPF

Christian Leray - Rennes 2 - França

Colette Noyau - París X - França

Cristiane Dias - UNICAMP

Eduardo Guimarães - UNICAMP

EniPuccinelli Orlandi- UNICAMP

Flávio Loureiro Chaves - UFRGS

Gema Sanz Espinar - Universidad de Madrid - Espanha

Gesualda Rasía - UFPR

Gladys B. Morales - Universidad Nacional de Rio Cuarto - Argentina

Hélène Leclercq - IUFM - Université de Franche-Comté

Héliane Kohler - Université de Franche-Comté

José Horta Nunes - LINESP

Luiz Francisco Dias - UFMG

Maria Cleci Venturini - UNICENTRO

María Elena Villecco - Universidad de Tucumán - Argentina

María José R. Faria Coracini - UNICAMP

María Josefina Garat - Universidad de Tucumán - Argentina

Véronique Daleth - USP 


\section{Capa e Projeto Gráfico Originais}

Mirian Rose Brum-de-Paula

Projeto Gráfico

Rejane Arce Vargas

\section{Diagramação}

Juciele Pereira Días

Entrevista e Revisão

Beatriz Eckert-Hoff

Marluza da Rosa

\section{Transcrição}

Marluza da Rosa

Periodicidade

Trimestral

\section{Editora}

Programa de Pós-Graduação em Letras

Universídade Federal de Santa María

Prédio 16, CE, sala 3222 - Bloco A2

Campus Universitário Camobi

$97105-900$ - Santa Maria, RS - Brasil

Fones: 0xx 5532208359 ; Oxx 5532208025

Email:ppgl@mail.ufsm.br

Site : www.ufsm.br/ppgletras

\section{Data da Efetiva Círculação}

Fevereíro de 2010

\section{Solicita-se permuta}

